\title{
TESTES E VALIDAÇÃO DO FUNCIONAMENTO DOS SISTEMAS FRENAGEM DE EMERGÊNCIA AUTÔNOMA, ESTUDO DE EQUIPAMENTOS E MÉTODOS DE AVALIAÇÃO VISANDO PROTOCOLOS NCAP
}

\author{
Pedro Henrique Silva Stano, Marcelo Massarani \\ Escola Politécnica da USP \\ e-mails: pedrostano@gmail.com, massarani@me.com.
}

\section{RESUMO}

A indústria automotiva no cenário atua passa por uma fase dita como transitória, onde os conceitos de em relação ao veículo mudaram, e seguem duas novas tendências, veículos elétricos e autônomos. Este trabalho abrange sob o tema de tecnologias de base para veículos autônomos, sob o ponto de vista de segurança veicular ativa e passiva, que é a frenagem de emergência autônoma conhecida pela sigla AEB. O objetivo do trabalho é verificar a viabilidade em termos dos equipamentos necessários para os testes do funcionamento dos parâmetros e dos sistemas de controle embarcados no veículo, sob a perspectiva dos recursos mínimos bem como caracterizando quais equipamentos necessários para adequar ao futuro protocolo Latin NCAP, o qual avalia os veículos quanto à segurança veicular, e expõem aos usuários (consumidores) os resultados de desempenho nos testes relacionados à segurança veicular.

\section{INTRODUÇÃO}

Este artigo tem como motivação o estudo de viabilidade e implantação de testes de Sistemas de Frenagem de Emergência Autônoma - Autonomous Emergency Braking (AEB System), visando à efetividade do funcionamento e sugerir como proposta de redução de acidentes. De modo a apresentar à aplicação e implantação das áreas de conhecimento da Engenharia Automotiva em específico a área de Segurança Veicular, utilizando como base de análise o protocolo Euro NCAP versão 2.0.1 publicada em novembro de 2017, a fim de avaliar e validar os sistemas de frenagem de emergência autônoma "Autonomus Emergency Braking AEB" através de testes de campo.

Analisando o cenário da Segurança Veicular nos dias de hoje no Brasil e nos países Latinos os quais apesentam altos índices de acidente, é necessário assegurar o bom funcionamento de itens como o AEB, que podem vir a contribuir com a redução de mortos e feridos no trânsito, o que vai de encontro com os objetivos e programas "Desenvolvimento sustentável" e "Década de Ação pelo Trânsito 2011-2020", da Organização das Nações Unidas - ONU.

O presente trabalho abrange as áreas de segurança ativa e passiva, visto que a Frenagem de Emergência Autônoma (AEB) é um sistema de segurança ativa, o qual sua função identificadora é evitar acidente, atuando antes da colisão, porém segundo o protocolo Euro NCAP o seu funcionamento está diretamente ligado a prevenir a segurança não só dos 
ocupantes do veículo com o sistema AEB bem como o os ocupantes dos veículos terceiros quanto às colisões e o efeito chicote ${ }^{1}$ (whiplash), prevenindo a integridade dos ocupantes adultos nos dois veículos (EUROPEAN NEW CAR ASSESSMENT PROGRAMME, 2017).

\section{OBJETIVO}

Definição dos aspectos técnicos envolvidos para execução de ensaios de avaliação dos sistemas de frenagem de emergência autônoma visando facilitar a implantação dos testes conforme protocolo NCAP (New Car Assessment Programme) nas montadoras e laboratórios do seguimento automotivo. Utilizando como método a avaliação das especificações descritas nos protocolos estudando viabilidade de recursos e equipamentos necessários para se avaliar efetivamente o funcionamento do AEB, definindo assim os recursos mínimos para execução dos testes, podendo facilitar o desenvolvimento dos sistemas de AEB dentro das montadoras nacionais.

\section{FRENAGEM DE EMERGÊNCIA AUTÔNOMA}

\subsection{DEFINIÇÃO DE AEB}

Definição segundo o instituto Euro NCAP Autonomous Emergency Braking (AEB System) Frenagem de Emergência Autônoma: Frenagem que é aplicada automaticamente pelo veículo em resposta à detecção de uma colisão provável para reduzir a velocidade do veículo e potencialmente evitar a colisão (EUROPEAN NEW CAR ASSESSMENT PROGRAMME, 2017).

\section{ANÁLISE DE RECURSOS E PARÂMETROS}

Para que um veículo seja elegível aso testes AEB, primeiramente o protocolo estabelece que o veículo a ser testado necessite ter um bom desempenho nos testes de efeito chicote "whiplash". O teste whiplash consiste em testar os assentos e encostos de cabeça, o conjunto é montado sob um trenó ("Sled") usando um manequim ("BIO RID Dummy") de impacto traseiro de baixa velocidade. São realizados três testes dinâmicos, representando as severidades mais comuns de acidentes conhecidas por causar lesões, juntamente com uma avaliação da geometria dos apoios de cabeça dianteiros e traseiros devendo seguir os critérios de avaliação do protocolo Euro NCAP. Validando o bom funcionamento quanto ao funcionamento dos bancos bem como os sistemas de retenção como cintos e prétensionadores. (EUROPEAN NEW CAR ASSESSMENT PROGRAMME, 2011).

Os Sistemas que trabalham principalmente em baixas velocidades são classificados com "AEB City systems". Os sistemas que trabalham nas velocidades médias e mais altas são os "AEB Inter-Urban systems".

\subsection{TIPOS DE TESTES}

O objetivo dos ensaios é testar os componentes, sensores quanto ao seu funcionamento, e identificar se são capazes de atender ao propósito de auxiliar o condutor em momentos de emergência onde estiverem distraídos, desatentos ou desacordados Em relação aos testes do sistema de frenagem de emergência autônoma AEB é dividido em três tipos: "Low Speed City System" (sistema de baixa velocidade para cidades) ou "AEB City, High Speed Inter- 
Urban System" (sistema de alta velocidade interurbano, rodovias) ou "AEB Inter-Urban" e por último "Pedestrian System" (sistema de segurança ao Pedestre), o qual não será analisado neste trabalho. (EUROPEAN NEW CAR ASSESSMENT PROGRAMME, 2017, p. 1, tradução nossa).

\subsection{TESTES DE BAIXA VELOCIDADE (AEB CIDADE)}

Testes de baixa velocidade ou "low speed city system (AEB CITY)", são de um modo geral relacionada com situações típicas encontradas dentro das cidades. De maneira indireta o sistema estará testando os sensores (radar, lidar/laser e câmera) quanto a sua capacidade de detecção dos eventos a frente do veículo, e o tempo de resposta do módulo de controle ECU quanto à resposta em emitir os avisos sonoros visuais e por fim se o sistema irá efetivamente parar o veículo caso não haja atuação por parte do condutor. Os testes de sistema de baixa velocidade para cidades ("AEB City") o veículo sob teste VUT ("Vehicle under test") serão realizados nas velocidades de $10 \mathrm{~km} / \mathrm{h}$ até $50 \mathrm{~km} / \mathrm{h}$ variando de cinco em cinco quilômetros por hora. O teste consiste em colocar o veículo na velocidade estabelecida, quando estiver estabilizado na velocidade o mesmo deve se aproximar do alvo global de veículo GVT ("Global Vehicle Target"), e sem que haja nenhuma intervenção por parte do condutor para frear o veículo, o veículo deve reduzir a velocidade e parar de forma autônoma, avaliando o sistema. Outra variante figura 1, é o "offset" o alinhamento entre o veículo sob teste VUT e o veículo alvo GVT, serão testados em cinco situações:

- "Offset" $0^{\circ}$ - Veículo sob teste VUT totalmente alinhado com o veículo Alvo GVT;

- "Offset" $-50^{\circ}$ - Veículo sob teste VUT deslocado a esquerda 50\% da largura total, em relação ao centro do veículo Alvo GVT;

- "Offset" $-75^{\circ}$ - Veículo sob teste VUT deslocado a esquerda $25 \%$ da largura total, em relação ao centro do veículo Alvo GVT;

- "Offset" $+50^{\circ}$ - Veículo sob teste VUT deslocado a direita 50\% da largura total, em relação ao centro do veículo Alvo GVT;

- "Offset" $+75^{\circ}$ - Veículo sob teste VUT deslocado a direita $25 \%$ da largura total, em relação ao centro do veículo Alvo GVT;

(EUROPEAN NEW CAR ASSESSMENT PROGRAMME, 2017, p. 5, tradução nossa)

Figura 1 - Representação do "offset", alinhamento entre os veículos.

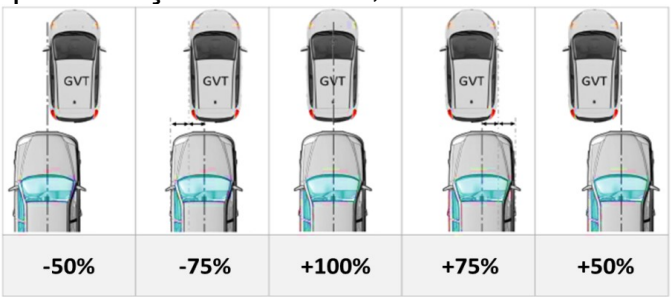

Fonte: www.euroncap.com

\subsection{TESTES DE ALTA VELOCIDADE (AEB INTERURBANO)}

Os testes referentes aos sistemas AEB em condições de alta velocidade também conhecidos como "high speed inter-urban (AEB Inter-urban)" em rodovias, serão divididos em três tipos de situações:

$1^{\circ}$ - O veículo sob testes VUT terá que realizar uma parada brusca, que consiste em representar uma situação onde o veículo está trafegando por uma rodovia e o trânsito para 
repentinamente a velocidade vai variar de $30 \mathrm{~km} / \mathrm{h}$ até $80 \mathrm{~km} / \mathrm{h}$ variando de cinco em cinco quilômetros por hora.

$2^{\circ}$ - O veículo sob testes VUT estará seguindo o veículo alvo GVT, em uma determinada velocidade que vai variar $30 \mathrm{~km} / \mathrm{h}$ até $80 \mathrm{~km} / \mathrm{h}$ variando de cinco em cinco quilômetros por hora e terá que realizar uma freada brusca, reduzindo consideravelmente a velocidade, que consiste em representar uma situação onde o veículo está trafegando por uma rodovia e é fechado por outro veículo com uma velocidade inferior.

$3^{\circ}$ - O veículo sob testes VUT estar seguindo o veículo alvo GVT, em uma determinada velocidade a $80 \mathrm{~km} / \mathrm{h}$ e terá que realizar uma freada branda, reduzindo consideravelmente a velocidade a $50 \mathrm{~km} / \mathrm{h}$, que consiste em representar uma situação onde o veículo está trafegando por uma rodovia e há uma desaceleração do trânsito. As condições de offset assim como nos testes de "AEB City" valem também para "AEB Inter-Urban".

\section{ANALISE DE APLICAÇÕES E RECURSOS}

Para sintetizar as aplicações e recursos é necessário analisar o processo de testes como uma malha de controle, sendo possível associar como o conceito descrito pelo Dr. Paulo Miyagi quando ele diz em seu livro "[...] Do ponto de vista teórico esta classe de sistemas é classificado na área de Sistemas a Eventos Discretos (SED) e operacionalmente a técnica de controle utilizada é denominada Controle Programável [...]" (MIYAGI, 1996), significa que, todo o processo de testes descritos no protocolo pode ser dividido em eventos discretos, onde cada ação a ser executada pelos atuadores será um evento e possuirá uma variável de controle e uma variável a ser controlada, para que assim no final do processo se obtenha a execução dos testes dentro dos parâmetros e requisitos do protocolo, bem como a aquisição dos dados para validar a parametrização dos sistemas embarcados no veículo, a qual representa outra malha de controle.

No capitulo 4 Equipamentos de Medição (“measuring equipment"), estão especificados no item 4.1.1 não exatamente os equipamentos que devem ser usados nos testes, mas estabelece que o veículo sob teste (VUT) e o veículo alvo (GVT) devem ter suas informações/dados sincronizados por um DGPS, sendo que os dados dinâmicos tanto do veiculo sob testes (VUT) quanto do veículo alvo (GVT), devem ser gravados a uma frequência $100 \mathrm{~Hz}$. O protocolo não determina quais devem ser os equipamentos para a execução, monitoramento e aquisição de dados, estabelecendo apenas os dados e critérios relevantes para validação do funcionamento do sistema AEB. Ficando a critérios dos executantes dos testes determinarem quais equipamentos utilizarão para garantir os parâmetros e critérios estabelecidos. Sendo necessário analisar o capítulo 4 na integra para identificar quais as variáveis estão envolvidas no teste. (EUROPEAN NEW CAR ASSESSMENT PROGRAMME, 2017, p. 6, tradução nossa).

Analisando o capítulo 4 o item 4.2 Variáveis e Medições ("Measurements and Variables"), é possível isolar as 5 variáveis físicas a serem medias:

- Tempo;

- Posição (distância);

- Velocidade;

- Velocidade angular ("Yaw");

- Aceleração.

Em relação ao item 4.3 o protocolo estabelece que veículo sob testes VUT e o veículo alvo GVT devem ser instrumentados com sistema de aquisição, com a seguinte precisão:

- Precisão quanto à velocidade do VUT ao GVT de $0.1 \mathrm{~km} / \mathrm{h}$; 
- Precisão da posição lateral e longitudinal de 0.03 m entre o VUT e GVT;

- A taxa de guinada, ou velocidade angular do entre o VUT e GVT devem se manter em $0.1 \%$.

- O VUT e o GVT devem manter $0.1 \mathrm{~m} / \mathrm{s}^{2}$ de precisão na aceleração longitudinal;

- A velocidade do volante do veículo sob testes VUT deve se manter em $1,0^{\circ} / \mathrm{s}$

O item 4.4 Filtragem dos Dados ("Data Filtering") diz respeito ao processamento dos dados, ou seja, como os sinais de aquisição de dados serão tratados para gerar o resultado dos testes. Os critérios abaixo devem ser considerados:

- Para velocidade e posição deve-se considerar o sinal "overall”, o que significa sinal bruto/puro sem filtro.

A aceleração, taxa de guinada (velocidade angular Yaw) e a força do volante serão necessárias aplicar um filtro eletrônico ("Butterworth" 12-pole) transformando a sua resposta em uma frequência, e garantindo melhor planicidade nas curvas, melhorando a qualidade dos resultados, com uma frequência de corte de $10 \mathrm{~Hz}$. (EUROPEAN NEW CAR ASSESSMENT PROGRAMME, 2017, p. 6 e 7, tradução nossa)

Analisando o protocolo, a lista de equipamentos e os requisitos quanta aquisição de dados e processamentos dos dados, entende-se que é necessário um controle de malha fechada, ou seja, todos os requisitos dos testes serão colocados neste controlador lógico programável (CLP), a qual atuará monitorar e corrigir o processo de testes a fim de atingir os objetivos estabelecidos pelo protocolo, bem como utilizar os dados de monitoramento para gerar os relatórios de analise. Todos os eventos ditos como variáveis físicas serão tratadas como variáveis de controle dentro da malha de controle.

Desta forma é possível estabelecer que nos testes AEB, serão necessários os seguintes controles (variáveis controladas):

- Direção/Volante

- Pedal de freio e acelerador

- Controle longitudinal

- Controle da posição global em relação ao veículo Alvo (GVT), bem como a posição do veículo na pista.

- Controle de aproximação entre o veículo sob teste e o veículo alvo (GVT).

Sempre levando-se em conta as variáveis de controle: tempo; posição (distância); velocidade; velocidade angular ("YAW") e aceleração.

Para atender este requisito do protocolo, é necessário utilizar três GPS de precisão amostral e capacidade de registro de dados dinâmicos com uma frequência de pelo menos $100 \mathrm{~Hz}$. Sendo um instalado na pista o qual é conhecido como base central (base station) representando o zero absoluto da posição global da pista, um será instalado no veículo sob teste VUT e o outro no veículo alvo GVT. A comunicação entre os GPS será feita através de frequência de rádio com frequência de transmissão que vai variar de $2 \mathrm{GHz}$ a $5 \mathrm{GHz}$, os GPS's devem fornecer informações de posição (latitude e longitude) com precisão global de pelo menos $1,0 \mathrm{~cm}$, do veículo sob teste (VUT) e do veículo alvo (GVT). O GPS da base central será o centralizador das informações, receberá as posições dos outros dois GPS, fará um pré-processamento e enviará as informações para a unidade de controle embarcada nos veículos. A unidade de controle processa as informações de posição de cada veículo como um sinal de "erro", ou seja, o controlador deve atuar na malha de controle para corrigir o sistema a fim de controlar as variáveis envolvidas, atingindo o setup feito do teste. As figuras 2 AEB City e 3 AEB Inter-urban é uma representação esquemática do sincronismo entre os GPS's. 
Figura 2-31 - Representação do sincronismo dos GPS's nos testes AEB City.eAEB Inter-Urban

Fonte: O próprio autor.

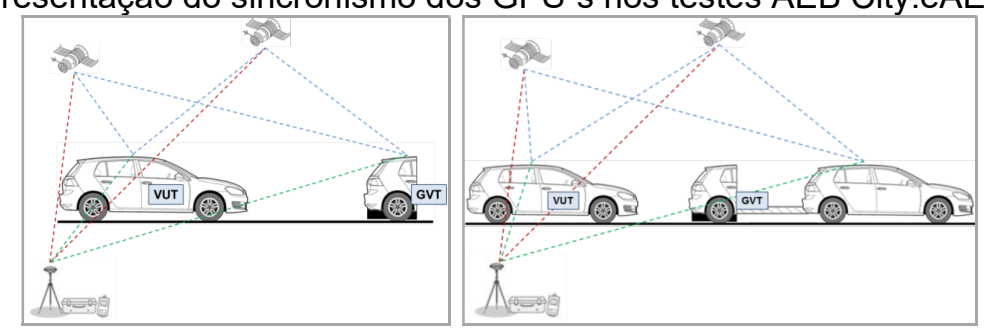

O controlador embarcado no veículo receberá as informações de posicionamento vindas da base central (GPS base station), e com as informações vai calcular o "erro" e mandará sinais de correção aos atuadores corrigindo a malha de controle. A atuação do controlador nesta situação será no intuito de corrigir uma ou mais das cinco variáveis de controle, tempo, distância, velocidade, velocidade angular e a aceleração. Serão necessários minimamente atuadores para controlar a direção/volante e os pedais de freio e acelerado, podendo ainda haver uma terceira variação com o controle de troca de marchas e consequentemente um para o pedal de embreagem.

Os atuadores de volante conhecidos como "steering wheel robot" (robô de volante/direção), são no geral compostos por um aro com diâmetros que variam de $293 \mathrm{~mm}$ a $386 \mathrm{~mm}$, acoplados/montados no volante do veículo, possui uma estrutura que será travada no assoalho do veículo, onde em sua outra extremidade estará o motor de passo que será efetivamente o responsável por movimentar o volante. $\mathrm{O}$ motor recebe os sinais vindos do controlador e movimentam o volante em função do sinal de correção.

O controle dos pedais também chamados de "combined brake and accelerator robot" (Robô combinado de freio e acelerador), é composto por dois atuadores, um irá controlar o acelerador do veículo o segundo será responsável pelo controle do pedal dos freios. Existem duas variações destes atuadores os eletropneumáticos, e os atuadores compostos por motor de passo.

Os eletropneumáticos são compostos por dois atuadores pneumáticos um para cada pedal, e seu controle é feito através de abertura e fechamento de válvulas, sendo necessária uma unidade de produção de ar comprimido, sendo essa uma das razões pela qual não são viáveis.

Os atuadores com motor de passo são mais viáveis para testes dinâmicas como, por exemplo, o AEB. No geral são compostos de duas hastes que serão fixadas sob os pedais e acionados por dois motores de passo, os motores receberam os sinais vindos do controlador e movimentam as hastes no intuito de acelerar e freia o veículo, conforme a necessidade de controle.

\section{ALTERNATIVAS PARA MEDIÇÃO DE VARIÁVEIS dE CONTROLE}

As variáveis definidas no protocolo Euro NCAP para testes de AEB no item 4.2 são eventos discretos (físicos), desta forma existem várias formas de se medir e fazer a aquisição dos dados/sinais. A indústria de automação de controle nos últimos anos se desenvolveu muito em termos de sensores ópticos, sensores de efeito Doppler, radares e sensores eletromecânicos, isso se deve ao grande avanço da eletrônica que proporciona uma ótima acurácia e boa resolução e precisão dos sinais.

Dentro do senário de testes e ensaios automotivos existem quatro tecnologias que se destacam para medição destas variáveis, que são: 
- Laser;

- Radar;

- Sensor óptico;

- Sensor eletromecânico.

\subsection{LASER E RADAR}

Os sensores laser oferece uma boa exatidão de medição/aquisição que e utilizam a tecnologia de "interferometria" basicamente utiliza o efeito Doppler o qual também é utilizada nos radares. Seu funcionamento é a resposta em frequência de uma onda propagada, sonora ou visual, e sua resposta e função do tempo, ou seja, é posicionado um emissor de onda e ao lado ou no mesmo dispositivo um receptor, estes equipamento vai emitir uma onda de comprimento conhecido, quando essa onda se colide com a variável controlada (objeto) a qual se deseja mediar a velocidade, ela sofrerá uma deflexão gerando uma resposta ao receptor que será igual à velocidade de aproximação do objeto em relação ao emissor. A aceleração, deslocamento e tempo serão baseados em um processamento do sinal de resposta, basicamente será dado pela integração do sinal em função do tempo. O equipamento pode ser montado na dianteira do veículo sob teste VUT, e outro na traseira GVT, sendo necessário, um equipamento de aquisição de dados para, receber, processar e enviar um sinal de erro para correção dos atuadores responsáveis por guiar os veículos.

\section{2 ÓPTICA}

Os sensores ópticos são largamente utilizados na área de controle e automação. Os mais comuns encontrados no mercado são os sensores do tipo reflexivo em conjunto com circuitos eletrônicos digitais. O sensor consiste em um emissor infravermelho (foto-diodo) e um receptor infravermelho (foto-transmissor), encapsulados em conjunto dentro do mesmo transdutor. O funcionamento deste tipo de sensor tem como princípio a emissão de uma luz através do diodo e a deflexão da luz quando "refletida" sob o objeto que se quer medir a velocidade e a distância. A resposta será igual a velocidade de aproximação do receptor. A integração deste sinal de velocidade será a aceleração e deslocamento (distância)

A tecnologia por imagens de câmeras de alta velocidade também se enquadra como uma forma de medir velocidade através da óptica. É uma tecnologia relativamente nova, porém oferece uma boa acurácia e precisão dos resultados. $O$ funcionamento é relativamente simples, o equipamento é composto de uma espécie de calota que possui alguns alvos ("target's"), os quais servirão de referência para uma câmera de alta velocidade capturas imagens e calcular a velocidade através de um "software". As outras variáveis aceleração e distância serão resultados de um pós-processamento.

\subsection{SENSOR ELETROMECÂNICO}

Dentro da indústria automotiva se desenvolveu um equipamento para fazer a aquisição da velocidade, conhecido como "quinta roda", um instrumento fácil de utilizar, consiste de um suporte montado no veículo com ajuste de largura e altura, onde uma roda montada sob um eixo fica em contato com o solo, além disso, este instrumento possui um sensor do tipo tacogerador de alta resolução que medem a velocidade através das revoluções/ciclos, sensor um gerador DC de ímã permanente, acoplado mecanicamente no eixo em que se deseja medir a velocidade, a tensão de saída é proporcional a velocidade do eixo. A partir do sinal de velocidade é possível integrar o sinal no tempo e obter a aceleração e deslocamento, e ainda é 
possível obter o tempo. Para a utilização deste equipamento nos testes AEB seria necessário um hardware com alta capacidade de processamento dos dados, para que fossem enviados os sinais de erro para a correção dos atuadores de controle de aceleração, frenagem e direção.

Outro equipamento customizado para a área automotiva é um sensor montado diretamente na roda do veículo "Speed Wheel" que aquista à distância e velocidade através das revoluções do eixo do veículo. Seu funcionamento é basicamente o mesmo da quinta roda, um sensor tacogerador que é o responsável por contar as revoluções, e gerar a resposta de velocidade, aceleração e distância a partir destes sinais.

Desta forma com o este dispositivos é possível medir e fazer a aquisição de quatro das variáveis físicas: Velocidade, aceleração e tempo. Porém este método seria valido apenas para aquisição das variáveis de velocidade, aceleração e tempo, visto que o protocolo determinar que informações de posição (latitude e longitude) com precisão global de pelo menos $1,0 \mathrm{~cm}$, do veículo sob teste (VUT) e do veículo alvo (GVT), devam ser medidas por GPS's.

\section{ALVO GLOBAL DE VEÍCULO - GVT}

Nos testes de validação dos sistemas autônomos de frenagem o GVT (Global Vehicle Target) em tradução livre "alvo global de veículos", consiste em um dos equipamentos com grande importância dentro dos testes, levando-se em consideração que o veículo sob testes irá ao encalço do GVT tanto nos testes de "city" quanto no "Inter-urban", sendo o "target" a referencia para testar o funcionamento dos componentes/sensores de detecção embarcado no veículo (câmeras, sensores, radares).

O Protocolo Euro NCAP - AEB Systems Version 2.0.1, Novembro de 2017 descreve no capítulo 5 item 5.1 especifica que o GVT, deve ser uma réplica com atributos visuais típicas de um veículo M1, no item 5.1.2, o protocolo estabelece que GVT tenha que proporcionar a detecção dos sensores embarcados no VUT tais como Radar (24 a 77GHZ), laser e as câmeras. Analisando o fato do Latin NCAP ainda não ter incluído os testes de AEB nos protocolos, considerar uma versão anterior do protocolo Europeu para o GVT, visto que se tratava de uma versão mais simples a qual atenderia as condições dos testes com um valor relativamente mais barato (EURPEAN NEW CAR ASSESSMENT PROGRAMME, 2013, p. 7, tradução nossa).

O protocolo Euro NCAP não restringe o uso de apenas uma forma de GVT, podem ser usados vários tipos de simulacros, podendo ser usado outro veículo até mesmo reproduções em fibra de vidro, balões com o formato se assemelhando as formas do veículo ou até mesmo um "mock-up" um modelo feito a partir da secção traseira do veículo. Os testes AEB não possuem o caráter destrutivo, considerando o fato de poder haver colisões durante os ensaios, são utilizados alvos flexíveis possuindo características semelhantes às de um automóvel em termos de secção transversal, rodas, e até mesmo a aparência visual.

\subsection{GVT PARA TESTES DE BAIXA VELOCIDADE}

Para os testes "city" onde o "target"/alvo ficará estático ou estacionário, geralmente são feitos de plástico, como um balão. Os radares embarcados no VUT, não possuem a capacidade de detectar os alvos feitos de plástico, sendo assim necessário que possuam fitas prateadas, folha de metal ou refletores de radar para torna-los detectáveis. 


\subsection{GVT PARA TESTES DINÂMICOS DE ALTA VELOCIDADE}

Os testes que envolvem o VUT e GVT em movimento são mais complexos no que diz respeito ao GVT, exigira que o alvo se movesse servindo de guia para o VUT durante o teste, ou seja, o veículo sob testes irá ao encalço do alvo, portanto o tempo, posição, velocidade e aceleração do alvo devem ser controlados com precisão. Devido aos parâmetros requeridos pelo protocolo torna-se extremamente complexo e difícil de realizar as manobras/ensaio com a atuação humana, sendo recomendada a utilização no veículo de apoio um sistema controlado por sensores e atuadores, tais como os robôs já citados anteriormente.

\section{CAMPO DE PROVAS}

Os testes devem ser executados em um campo de provas ("Test track"), com algumas características especificadas e descritas pelo protocolo, tais como:

- A superfície da pista de testes deve estar seca e livre umidade, de forma uniforme, ou seja, a pavimentação deve contemplar um sistema de drenagem, para conter quaisquer fontes hídricas que venha a atingir a superfície.

- Apresentar uma estrutura pavimentada sólida, não podendo haver irregularidades (Ex: rachaduras, tampas de inspeção ou refletores), os quais poderiam gerar erros de anormais dos sensores dentro de uma distância lateral de $3,0 \mathrm{~m}$, para cada lado da trajetória de testes, resguardando $30 \mathrm{~m}$ à frente do veículo sob teste (VUT) ao final do ensaio.

- Ao longo da pista são permitidos marcações/faixas típicas de ruas e estradas, porém desde que estás não estejam dentro dos $3,0 \mathrm{~m}$ previstos de cada lado. Faixas e marcações cruzando a trajetória de testes não podem estar presentes na área onde for ocorrer a ativação do sistema AEB ou a frenagem após o "Forward Collision Warning" - FCW (Aviso de colisão frontal). em resumo os arredores da pista devem estar livres de quaisquer tipos de obstáculos Para que isso não atrapalhe ou influenciem de alguma forma os testes com leituras anormais ou falsas dos sensores de monitoramento.

- Inclinação consistente entre o nível de 1\%. A superfície de ensaio deve ter um coeficiente de travagem mínimo "Peak Braking Coefficient" - PBC (Coeficiente de travagem máxima) de 0,9 .

(EUROPEAN NEW CAR ASSESSMENT PROGRAMME, 2017, p. 11, tradução nossa)

O protocolo descreve algumas características exigidas em termos das condições e características de pista, porém não estabelece o comprimento para executar os testes. Isso ocorre porque este fator vai estar diretamente relacionado com a massa do veículo a ser testado, bem como suas características dinâmicas ("Powertrain", influências aerodinâmicas) para atingir as velocidades determinadas nos testes.

Considerando uma situação hipotética em que um condutor esteja trafegando a $70 \mathrm{~km} / \mathrm{h}$ em uma via comum com um coeficiente de atrito estimado de $\mu=09$, em um veículo popular de categoria M1 com massa aproximada de $900 \mathrm{~kg}$, nesta situação deve-se considerar que condutor identificou e reagiu em 1 segundo a presença de outro veículo parado na mesma via sem possibilidade de realizar uma manobra evasiva para desvio. Abaixo se apresenta os cálculos relativos ao deslocamento e a energia necessária para se para o veículo nestas condições. Ao se considerar a energia do movimento, ou seja, a energia cinética envolvida nesta situação será possível estabelecer o quanto de energia será necessário para desacelerar e 
parar o veículo e desta forma descrever alguns parâmetros em termos de distância e comprimento de pista para parar o veículo.

$$
\begin{gathered}
\frac{70.000 m-3.600 s=}{X m-1 s} X=19,44 m \\
D=\frac{v^{2}}{250 \mu} \\
D=\frac{70^{2}}{250 x(0,9)}=21,78 m \\
E c=\frac{m \cdot v^{2}}{2} \\
v=70 \frac{k m}{h}=70 \frac{1.000 m}{3 \cdot 600 \mathrm{~s}}=19,44 \mathrm{~m} / \mathrm{s} \\
E c=\frac{900 \cdot(19,44)^{2}}{2}=170,14 \times 10^{3} \mathrm{~J}
\end{gathered}
$$

Para está situação hipotética o condutor percorreu 19,44m antes de acionar os freios, e depois de acionados os freios percorreu mais $21,77 \mathrm{~m}$ até desacelerar totalmente, ou seja, o condutor precisou de exatamente $41,21 \mathrm{~m}$ e uma energia cinética de $170,14 \times 10^{3} \mathrm{~J}$ para desacelerar e parar por completo o veículo antes de uma colisão. Podendo assim concluir que, quanto maior for a massa e a velocidade, e por tanto as energias cinética, maior será a energia de desaceleração o que significa também que será maior a distância necessária para a frenagem. Levando-se em conta os resultados acima obtidos, é possível estabelecer que um veículo com características semelhantes em uma condição de testes "AEB City", ou "AEB Inter-urban", do ponto de inicio do teste ao momento de desaceleração completa do veículo serão aproximadamente $71,21 \mathrm{~m}$, considerando os $41,21 \mathrm{~m}$ para parar o veículo e os $30 \mathrm{~m}$ metros de segurança requeridos pelo Protocolo. E este valor aumentara de acordo com a velocidade.

No Brasil existem alguns campos de provas privados e independentes, os quais atenderiam com os requisitos acima citados. Tais como o campo: Campo de ZF TRW, RANDON, Bridgestone, Pirelli, Campo de Provas da Marambaia, entre outros. Todos estes cumprem com dimensões requeridas, bem como coeficiente de atrito e inclinação máxima. Muito embora a maioria seja de inciativa priva a maioria estão à disposição para aluguel para terceiro.

\section{CONDIÇÕES CLIMÁTICAS}

Quando se considera ensaios/testes em ambiente aberto o clima é um dos fatores que pode influenciar nos resultados bem como na repetitividade dos resultados, visto que o veículo, os componentes testados e os instrumentos de medição podem variar com temperatura, pressão atmosférica, umidade relativa, luminosidade, ventos e chuvas. O protocolo da Euro NCAP é bem abrangente para testes de AEB pois seu range de temperatura varia de $5^{\circ} \mathrm{C}$ a $40^{\circ} \mathrm{C}$. Não podendo ser realizados os testes quando houver chuva e ou precipitações. A visibilidade horizontal deve ser superior a $1 \mathrm{~km}$. O vento no momento dos testes deve ser inferior a $10 \mathrm{~m} / \mathrm{s}$, para não afetar o desempenho dos GVT e VUT. O protocolo descreve que os testes sejam realizados a luz do dia e também preconiza que a luminosidade esteja acima de 2000 lux, não sendo recomendável a realização dos testes em momentos onde haja "sobras fortes", evitando assim interferências nos sensores. Do veículo e da instrumentação de testes. Todos os parâmetros em relação às condições climáticas devem ser registrados no início de cada teste e pelo menos a cada 30 minutos. Os parâmetros devem ser expressos da seguinte forma: Temperatura ambiente $\mathrm{em}^{\circ} \mathrm{C}$ (graus Celsos); 
Temperatura pista em ${ }^{\circ} \mathrm{C}$ (graus Celsios);

Velocidade e direção do vento em $\mathrm{m} / \mathrm{s}$.

Para este tipo de aferição os instrumentos mais recomendados seriam respectivamente:

Termo higrômetro para aferir as temperaturas;

Anemômetro para aferir a velocidade dos ventos.

Sendo recomendável anualmente à aferição e calibração destes instrumentos, de acordo com as normas e procedimentos RBC. (EUROPEAN NEW CAR ASSESSMENT PROGRAMME, 2017, p. 11, tradução nossa)

\section{CARACTERIZAÇÃO DE RECURSOS}

A caracterização dos recursos, e a definição dos equipamentos estão diretamente ligados ao objetivo específico deste trabalho, que é a definição dos recursos mínimos para execução dos testes dos sistemas de frenagem de emergência autônoma, e como consequência garantir o bom funcionamento e a efetividade deste sistema embarcado no veículo.

No que diz respeito ao desenvolvimento e aplicação destas teologias, cabe à segurança veicular validar a efetividade e o comprometimento do bom funcionamento de todos os sistemas.

Analisando os parâmetros e as exigências quanto ao controle das variáveis envolvidas nos testes e para atingir os resultados esperados pelo protocolo, a forma imparcial de avaliação dos equipamentos envolvidos, pode ser definida em uma matriz de decisão, tabela 1 abaixo.

Tabela 1 - Matriz de decisão dos equipamentos para testes de sistemas AEB.

\begin{tabular}{|l|c|c|c|c|c|}
\hline \multicolumn{1}{|c|}{ Variáveis de controle } & Tempo & Posição & Velocidade & $\begin{array}{c}\text { Velocidade } \\
\text { angular }\end{array}$ & Acele ração \\
\hline GPS & $\mathrm{x}$ & $\mathrm{x}$ & $\mathrm{x}$ & $\mathrm{x}$ & $\mathrm{x}$ \\
\hline Laser & $\mathrm{x}$ & $\mathrm{x}$ & $\mathrm{x}$ & & $\mathrm{x}$ \\
\hline Raddar & $\mathrm{x}$ & $\mathrm{x}$ & $\mathrm{x}$ & & $\mathrm{x}$ \\
\hline Sensor óptico & $\mathrm{x}$ & $\mathrm{x}$ & $\mathrm{x}$ & & $\mathrm{x}$ \\
\hline Sensor Eletromecânico & $\mathrm{x}$ & $\mathrm{x}$ & $\mathrm{x}$ & & $\mathrm{x}$ \\
\hline
\end{tabular}

Fonte: O próprio autor.

O GPS é o único equipamento capaz de medir a velocidade de guinada ("Yaw velocity"), que é exatamente a velocidade angular, sendo medida através do posicionamento do global, e o giroscópio. Além de ser o único equipamento que cumpre com os requisitos do protocolo em fornecer informações de posição (latitude e longitude) com precisão global de pelo menos 1,0 $\mathrm{cm}$, do veículo sob teste (VUT) e do veículo alvo (GVT). O capítulo 4 (tabela 1) no item 4.3 "measuring equipment" (equipamentos de medição) no subitem 43.1, sustenta e indica de forma indireta a necessidade do GPS quando descreve a precisão e as taxas de aquisição de dados das seguintes variáveis:

- Velocidade de aproximação do VUT para o GVT deve ser de $0.1 \mathrm{~km} / \mathrm{h}$;

- Posição lateral e longitudinal do VUT e GVT devem ser de $0,03 \mathrm{~m}$;

- A taxa de guinada entre o VUT e GVT deve ser de $0,1 \%$;

- Aceleração longitudinal entre VUT e GVT deve ser de $0,1 \mathrm{~m} / \mathrm{s}^{2}$;

- Velocidade de ângulo de volante de $1.0 \% \mathrm{~s}$.

(EUROPEAN NEW CAR ASSESSMENT PROGRAMME, 2017, p. 6, tradução nossa) 
Tabela 2 - Equipamentos de medição "measuring equipment"

\begin{tabular}{|l|}
\hline 4.3 \\
Measuring Equipment \\
Equip the VUT and GVT with data measurement and acquisition equipment to sample \\
and record data with an accuracy of at least: \\
- VUT and GVT speed to $0.1 \mathrm{~km} / \mathrm{h} ;$ \\
- VUT and GVT lateral and longitudinal position to $0.03 \mathrm{~m} ;$ \\
- VUT and GVT yaw rate to $0.1 \%$ \\
- VUT and GVT longitudinal acceleration to $0.1 \mathrm{~m} / \mathrm{s}^{2} ;$ \\
- VUT steering wheel velocity to $1.0 \% \mathrm{~s}$.
\end{tabular}

Fonte: www.euroncap.com/ Euro NCAP - Version 2.0.1, Novembro de 2017.

Ainda de acordo com a tabela 2 no item 4.3 "measuring equipment" (equipamentos de medição) no sub item 4.3.1, é possível descartar qualquer possibilidade dos testes serem executados totalmente por um piloto de teste, porque além de determina de forma indireta a necessidade dos GPS's para medir e fazer a aquisição dos dados durante a execução de testes, essas informações servirão também com "sinais de erro" para a correção dos parâmetros nos atuadores, o que guiará o veículo VUT a condições de testes do funcionamento do sistema de frenagem de emergência autônoma. Sendo necessário um sistema robotizado/automatizado com atuadores de controle de direção, aceleração e frenagem, os quais serão responsáveis por atuar no sentido de guiar o VUT e o GVT nas condições estabelecidas para os testes. (EUROPEAN NEW CAR ASSESSMENT PROGRAMME, 2017, p. 6, tradução nossa)

\subsection{LISTA DE EQUIPAMENTOS}

A lista de equipamentos abaixo representa uma solução possível em termos de equipamentos e recursos para execução dos testes. Os equipamentos desta lista prevêm uma condição testes onde haverá a necessidade de um piloto de testes para o VUT e um para GVT, porém a única atuação e interface dos pilotos no processo de testes serão no sentido de colocar o veículo em ordem de marcha, e acompanhamento para uma eventual falha e haver necessidade de abortar os testes. O processo de setup também é feito pelo piloto de testes, no "start" para o iniciar os testes será dado pelos pilotos, dessa forma o controlador passará a atuar no sistema no momento em que o pilo de aperta e segurar um botão no "joystick", o qual será explicado mais a frente, liberando a atuação para o sistema de controle, o operado permanecerá o todo o período do teste pressionando este botão "abortion button" também conhecido como "homem morto", se houver alguma emergência de qualquer natureza, e o piloto de testes soltar este botão, imediatamente o controle para de exercer qualquer tipo de atuação e controle. $\mathrm{O}$ veículo irá para na em sua própria inercia.

\subsubsection{ATUADORES}

(Robô de Direção).

Robô de direção/volante (atuador de volante)

Função: Controlar/Atuar no volante do VUT e GVT durante a execução dos testes, seguindo os parâmetros estabelecidos pelo protocolo. De acordo com o capítulo 3 item 3.2, o atuador deverá controlar e guiar o veículo em direção ao alvo GVT de acordo com o "overlap" (sobreposição) para o teste, a figura 4 exemplifica essa a correção necessária para o teste. 
Ainda de acordo com o protocolo no capítulo 4, o robô de volante deverá atuar no controle velocidade de ângulo de volante que deve ser igual a $1.0 \%$. (EUROPEAN NEW CAR ASSESSMENT PROGRAMME, 2017, p. 5, tradução nossa)

Quantidade: Nos testes "City" apenas um instalado no VUT, nos testes "inter-urban" serão necessários dois sendo um instalado no VUT e um no GVT respectivamente.

Figura 4 - Correção de direção, de acordo com sinal de erro.

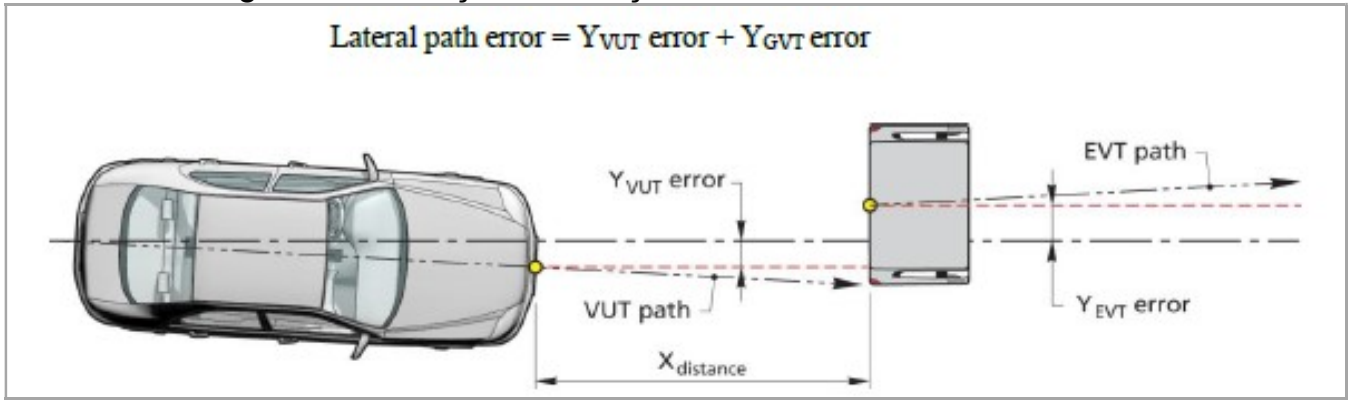

Fonte: Euro NCAP, protocolo de testes - Test Protocol -AEB Systems

\section{Robô controlador de aceleração e frenagem}

Robô para aceleração e frenagem do VUT e GVT.

Função: Controlar/Atuar na aceleração e frenagem do VUT e GVT durante a execução dos testes, de acordo com o capítulo 4, o atuará no sentido de controlar as variáveis de aceleração, velocidade, posição e consequentemente o tempo. Garantindo o cumprimento de todos os requisitos descritos no item 4.2 do protocolo.

Quantidade: Nos testes "City" apenas um instalado no VUT, nos testes "inter-urban" serão necessários dois sendo um instalado no VUT e um no GVT respectivamente.

\subsubsection{UNIDADE DE CONTROLE CLP}

Central Lógica Programável CLP. A unidade de controle deve possuir portas analógicas digitais. Deve possuir ao menos duas portas de comunica lógicas (entrada e saída), para controlar os atuadores/robôs de volante e pedais, podendo ser considerado uma terceira porta caso haja um robô para controle de troca de marchas. Além destas portas é necessária uma porta de comunicação de diagnóstico de bordo (OBD2 ("On board Diagnostics"), ou seja, que leia a CAN do veículo sob teste durante o testes, essa será a forma pela qual será possível validar a aquisição de dados do sistema, como o parâmetro do veículo. O controlador deve possuir um out/in para comunicação via rádio como os GPS e também uma porta analógica LAN para baixar os dados do sistema após os testes. Os equipamentos responsáveis pela captura dos sinais áudio visuais também deve possuir uma porta de entrada no controlador. Toda interface do controlador com o pilo de testes normalmente é feita por computador embarcado no veículo, sendo fixado em uma altura para facilitar a interface homem máquina. Em relação a malha de controle e a forma de controlar é possível aplicar um controle proporcional integral derivativo (PID), dessa forma o sinal erro será mais estável e minimizado pelo controle proporcional, um zero erro, ou seja, zerado pelo controle integral e a velocidade de resposta e antecipação será dada pela ação derivativa. Outras formas de controle como lógica "fuzzy" também podem ser utilizadas.

Função: Gerencialmente e processamento dos dados vindos dos equipamentos de monitoramento, bem como enviar sinais de controle para os atuadores (robôs). Garantindo a execução dos testes dentro dos padrões estabelecidos no protocolo. 
Quantidade: Nos testes "City" apenas um instalado no VUT, nos testes "inter-urban" serão necessários dois sendo um instalado no VUT e um no GVT respectivamente.

\subsubsection{MONITORAMENTO/PERIFÉRICOS:}

O controlador ou central lógica programável (CLP) trabalha no controle dos atuadores baseado nos sinais de posição global vindos dos GPS, sendo necessários alguns equipamentos periféricos que auxiliem no controle, tais como:

Rádio de comunicação e controle:

Função: Receber sinais analógicos digitais vindos do GPS, converter em uma frequência de rádio para transmitir ao controlador.

Quantidade: Serão sempre utilizados 3 rádios de comunicação, nos testes "City" serão instalados um no VUT, o segundo no "GPS base station" que será no zero absoluto do campo de provas. Nos testes "inter-urban" também serão necessários três, sendo um instalado no VUT, um no GVT e o terceiro no GPS que será no zero absoluto do campo de provas.

Medidor de Tempo dos Sinais de Aviso - (Warning Signal Timer)

Função: Hardware que irá capturar através de um microfone e uma câmera de vídeo respectivamente, o sinal áudio visual (FCW - "Forward Collision Warning"), emitido pelo veículo quando detectarem a eminência de uma possível colisão.

Através do da aquisição destes sinais será possível correlacionar como os tempos estabelecidos pelo protocolo, e validar os parâmetros do veículo.

Quantidade: Será necessário apenas um equipamento deste que será instalado no interior do veículo sob teste VUT.

\subsubsection{CONTROLE DOS ROBÔS:}

Função: Ao se fazer o setup os pilotos de teste podem ajustar o percurso utilizando o “joystick". Após o piloto de teste colocar o veículo em ordem de marcha e posicionar o veículo no campo de provas, ele apertará um botão que se encontra no joystick dando o start para o controlador iniciar os procedimentos de testes. Este botão é o responsável por finalizar e ou aborta os testes.

Quantidade: Nos testes "City" apenas um instalado no VUT, nos testes "inter-urban" serão necessários dois sendo um instalado no VUT e um no GVT respectivamente.

\subsubsection{GPS (SISTEMA DE POSICIONAMENTO GLOBAL)}

São equipamentos de posicionamento por satélite, onde cada satélite é rastreado por ondas de rádio, um emissor emite essas ondas que são posteriormente medidos por um receptor, desta forma sendo possível medir a velocidade de deslocamento, aceleração e velocidade, bem como posição em latitude e longitude.

Função: Nos testes de sistemas de frenagem de emergência, consistem em um dos equipamentos mais importantes desta lista devido ao fato de ser responsável por todos os resultados, bem como o será responsável por retroalimentar o controlador com sinais de correção para os atuadores. Também são responsáveis pela interação entre o VUT, GVT e o campo de provas garantido que os testes ocorram dentro dos parâmetros estabelecidos.

Quantidade: Assim como os rádios de comunicação sempre serão utilizados três GPS até pelo fato de trabalharem em conjunto. Nos testes "City" serão instalados um no VUT, o segundo no "GPS base station" que será no zero absoluto do campo de provas. Nos testes "inter-urban" também serão necessários três, sendo um instalado no VUT, um no GVT e o terceiro no GPS que será no zero absoluto do campo de provas. 
Observação: Estes GPS's não são de uso convencional/civil, são equipamentos de alta precisão de acordo com a tabela abaixo estes seriam os parâmetros necessários para garantir o desempenho dos resultados esperados.

Tabela 3 - Lista de GPS

\begin{tabular}{|l|l|l|l|l|l|}
\hline Manufacturer & Model & $\begin{array}{l}\text { Position } \\
\text { accuracy } \\
{[\mathrm{cm}]}\end{array}$ & $\begin{array}{l}\text { Speed } \\
\text { accuracy } \\
{[\mathrm{km} / \mathrm{h}]}\end{array}$ & $\begin{array}{l}\text { Update } \\
\text { rate } \\
{[\mathrm{Hz}]}\end{array}$ & Misc \\
\hline $\begin{array}{l}\text { Oxford Technical } \\
\text { Solutions }\end{array}$ & RT4002 & 2 & $\begin{array}{l}0.05 \\
\text { RMS }\end{array}$ & 250 & $\begin{array}{l}\text { IMU built in } \\
\text { RS232, Ethernet, CAN }\end{array}$ \\
\hline $\begin{array}{l}\text { Oxford Technical } \\
\text { Solutions }\end{array}$ & RT3002 & 2 & $\begin{array}{l}0.05 \\
\text { RMS }\end{array}$ & 100 & $\begin{array}{l}\text { IMU built in } \\
\text { RS232, Ethernet, CAN }\end{array}$ \\
\hline Racelogic $^{2}$ & $\begin{array}{l}\text { VBOX 3i } \\
\text { R10G10 }\end{array}$ & 2 & 0.1 & 100 & $\begin{array}{l}\text { IMU as separate component } \\
\text { RS232, USB, Bluetooth, CAN }\end{array}$ \\
\hline Trimble $^{3}$ & SPS461 & $1+1 \mathrm{ppm}$ & - & 20 & $\begin{array}{l}\text { No IMU } \\
\text { RS232, Bluetooth, Ethernet }\end{array}$ \\
\hline Javad $^{4}$ & Alpha & $1+1 \mathrm{ppm}$ & - & 100 & $\begin{array}{l}\text { No IMU } \\
\text { RS232, USB, Bluetooth }\end{array}$ \\
\hline Novaltel $^{5}$ & SPAN & $1+1 \mathrm{ppm}$ & - & $?$ & $\begin{array}{l}\text { IMU as separate component } \\
\text { RS232, USB, Ethernet }\end{array}$ \\
\hline $\begin{array}{l}\text { Corrsys-Datron } \\
\text { Sensorsysteme }\end{array}$ & CDS-GPS & 300 & 0.1 & 100 & USB, Ethernet \\
\hline Dewetron $^{7}$ & $\begin{array}{l}\text { DEWE- } \\
\text { VGPS-HS }\end{array}$ & 40 & 0.1 & 50 & RS232, USB \\
\hline
\end{tabular}

Fonte:www.oxts.com/www.racelogic.co.uk/www.trimble.com/www.javad.com/www.noval.com/www.cor rsys-datron.com/www.dewetron.com

As tabelas 4 e 5 representam respectivamente listas de equipamentos para realizar os testes de AEB de baixas e altas velocidades. Apresentam os equipamentos de controle, atuação e monitoramento, bem como periféricos e itens de montagem. Além dos equipamentos listados é necessário utilizar um dos campos de provas listados no capítulo 4.5, bem como os equipamentos para controle de condições climáticas do capítulo 4.6. Sendo recomendável que os executantes (montadoras e laboratórios) que se proponham a executar estes testes, tenham ou se enquadrem dentro dos padrões da ISO/IEC 17025, que são os requisitos gerais para competência de laboratórios de ensaio e calibração que é uma norma para sistema de gestão em laboratórios (ASSOCIAÇÃO BRASILEIRA DE NORMAS TÉCNICAS, 2005), o que pode garantir acreditação e qualificação dos resultados dos testes. 
Tabela 4 - Lista de equipamentos para testes de baixa velocidade (AEB Cidade)

\begin{tabular}{|c|c|c|}
\hline \multicolumn{3}{|c|}{ TESTES DE BAIXA VELOCIDADE (AEB CIDADE) } \\
\hline Item & Equipamentos & Quantidade \\
\hline 1 & Controlador & 1 \\
\hline 2 & Robô de volante & 1 \\
\hline \multirow{3}{*}{3} & 3.1 - Robô de pedais & 1 \\
\hline & 3.2 -Equipamento de montagem do Robô de pedais. & 1 \\
\hline & 3.3 - Suporte dos motores do Robô de pedais & 1 \\
\hline \multirow{3}{*}{4} & 4.1 - Um computador portátil ("Tablet") & 1 \\
\hline & 4.2 - Suporte de montagem para Computador & 1 \\
\hline & 4.3 - Software de integração de interface como o piloto de testes. & 1 \\
\hline 5 & Controle dos Robôs ("Joystick ") & 1 \\
\hline 6 & Entrada no controlador para leitura de CAN. OBD2 & 1 \\
\hline 7 & GPS do veículo sob testes VUT & 1 \\
\hline 8 & GPS do Alvo GVT & 1 \\
\hline 9 & GPS de base central na pista & 1 \\
\hline 10 & Rádio de comunicação para o GPS para o GVT & 1 \\
\hline 11 & Regulador de tenção para o GPS & 1 \\
\hline 12 & Suporte para o GPS & 1 \\
\hline 13 & Rádio de comunicação para o GPS para o VUT & 1 \\
\hline 14 & Rádio de comunicação para o GPS para o GVT & 1 \\
\hline 15 & Medidor de Tempo dos Sinais de Aviso - (Warning Signal Timer) & 1 \\
\hline 17 & Alvo GVT & 1 \\
\hline 18 & Cabos de comunicação e alimentação & $\begin{array}{c}\text { Não } \\
\text { informado }\end{array}$ \\
\hline
\end{tabular}

Fonte: O próprio autor. 
Tabela 5 - Lista de equipamentos para testes de Alta velocidade (AEB Interurbano)

TESTES DE ALTA VELOCIDADE (AEB INTERURBANO)

\begin{tabular}{|c|c|c|}
\hline Item & Equipamentos & Quantidade \\
\hline 1 & Controlador & 2 \\
\hline 2 & Robô de volante & 2 \\
\hline \multirow{3}{*}{3} & 3.1 - Robô de pedais & 2 \\
\hline & 3.2 -Equipamento de montagem do Robô de pedais. & 2 \\
\hline & 3.3 - Suporte dos motores do Robô de pedais & 2 \\
\hline \multirow{3}{*}{4} & 4.1 - Um computador portátil ("Tablet") & 2 \\
\hline & 4.2 - Suporte de montagem para Computador & 2 \\
\hline & 4.3 - Software de integração de interface como o piloto de testes. & 2 \\
\hline 5 & Controle dos Robôs ("Joystick ") & 2 \\
\hline 6 & Entrada no controlador para leitura de CAN. OBD2 & 1 \\
\hline 7 & GPS do veículo sob testes VUT & 1 \\
\hline 8 & GPS do veículo de suporte mais Alvo GVT & 1 \\
\hline 9 & GPS de base central na pista & 1 \\
\hline 10 & Rádio de comunicação para GPS base central na pista & 1 \\
\hline 11 & Regulador de tenção para o GPS & 2 \\
\hline 12 & Suporte para o GPS & 3 \\
\hline 13 & Rádio de comunicação para o GPS para o VUT & 1 \\
\hline 14 & Rádio de comunicação para o GPS para veículo de apoio + GVT & 1 \\
\hline 15 & Medidor de Tempo dos Sinais de Aviso - (Warning Signal Timer) & 1 \\
\hline 16 & GVT mais trenó para acoplar no veículo de apoio & 1 \\
\hline 18 & Cabos de comunicação e alimentação & $\begin{array}{c}\text { Não } \\
\text { informado }\end{array}$ \\
\hline
\end{tabular}

Fonte: O próprio autor.

\section{CONSIDERAÇÕES FINAIS}

Além das analises feitas e as listas de equipamentos existem outros aspectos a serem estudados tais como:

- O aspecto econômico: Em termos de compra dos recursos e equipamentos, é um fator relevante a ser considerado, visto que, os valores dos robôs e os GPS's são elevados, podendo ser um entrave para o desenvolvimento desta tecnologia dentro dos centros de engenharia das montadoras aqui instaladas. Pois o "payback" (retorno financeiro) será a razão direta da 
quantidade de veículos desenvolvidos e vendidos com essa tecnologia no país, pela quantidade de testes necessária para desenvolver um veículo com essa tecnologia embarcada. Como alternativa existe a viabilidade de contratação de empresas especializadas em testes,

- Análise dos equipamentos alternativos: Para execução dos testes é possível notar que existe outras possibilidades em termos de equipamentos para medição e aquisição de dados. Sendo necessário a validação do método dos mesmos junto ao instituto.

- Analise dos parâmetros do Sistema AEB para o transito nacional: A metodologia de testes prevista no protocolo utilizado pelo Euro NCAP o qual foi utilizado para fazer as analises deste trabalho e possivelmente serão os mesmo adotados pelo Latin NCAP, foram estabelecidos de acordo com situações típicas do trânsito europeu, sendo recomendável uma nacionalização para os testes no Brasil.

- Desenvolvimento de estudos junto a seguradoras: A proposta de mitigara e o grande potencial de reduzir os acidentes com o sistema de frenagem de emergência autônoma, seria relevante realizar testes nestes veículos promovendo junto ao CESVI (Centro de Experimentação e Segurança Viária), por exemplo, para comprovar a efetividade do sistemas e propor uma redução por exemplo nos seguros de veículos com estes sistema embarcado. Promovendo uma vantagem ao usuário (consumidor) tornando o veículo com este sistema mais atrativo, e consequentemente motivando as montadoras a adotarem o AEB nos veículos, e de modo mais significativo reduzindo os índices de acidentes.

\section{CONCLUSÃO}

Este trabalho teve como objetivo a viabilidade técnica em termos de equipamentos e recursos para implantação dos testes referentes ao sistema de frenagem de emergência autônoma. $\mathrm{O}$ AEB é uma tecnologia de base para veículos autônomos, as quais são amplamente estudadas e desenvolvidas em centros acadêmicos e de engenharia, porém muito pouco é feito em termos de metodologias de validação dos parâmetros através de testes. O grande desafio para este trabalho foi encontrar fontes com informações referentes aos métodos de ensaio, pelo fato de os testes serem feitos baseados em um protocolo dos institutos mercadológicos NCAP, e os centros de desenvolvimento acabam por adotar/seguir exatamente os recursos e equipamentos sugeridos indiretamente pelo protocolo.

As análises e a caracterizações em termos de recursos necessários foram baseadas no protocolo Europeu - Protocolo Euro NCAP - “AEB Systems Version” 2.0.1, novembro de 2017, o qual vem realizando e testando estes sistemas desde o ano de 2014.

Para caracterização dos recursos e equipamentos, os testes foram considerados como uma malha de controle, onde primeiramente se analisou os parâmetros a serem controlados bem como o resultado esperado. $\mathrm{O}$ passo seguinte foi necessário discretizar os eventos e também as variáveis de controle e variáveis controladas. Para assim encontrar soluções em termos de métodos de controle e atuação, com recursos e equipamentos disponíveis no mercado e indicados pelo protocolo. $\mathrm{O}$ aspecto de detalhamento de modo de controle poderia ter sido melhor explorado, o que talvez apresentaria melhores resultados em termos de alternativas para realizar os testes, demonstrando assim a importância da aproximação dos meios acadêmicos dos problemas encontrados na indústria. Sendo indicado como próximo passo estudos para levantamentos de dados e parametrização, e como consequência seria necessário à avaliação e validação do método alternativo junto ao instituto.

O instituto Latin NCAP publicou em junho de 2018 um boletim técnico: “Assessment Protocol Guideline" 2020 - 2023 (Diretrizes de avaliação do protocolo 2020 - 2023), este 
documento define as diretrizes e os aspectos técnicos envolvidos em termos de testes e avaliação dos próximos protocolos do Latin NCAP, entrando em vigor em dezembro de 2019. Dentro deste contexto o capítulo 7 do boletim, item 7.4.2 (LATIN NCAP NEW CAR ASSESSMENT PROGRAMME, 2018, p. 10), o instituto define que os veículos serão testados quanto aos sistemas de frenagem de emergência autônoma AEB e este será um critério mandatório para garantir a pontuação ("score") máxima de 5 estrelas. Os recursos e avaliações previstos pelo Latin NCAP para testes AEB são em síntese os mesmos no protocolo Europeu, desta forma o boletim endossa a contribuição deste trabalho, visto que a caracterização aqui apresentada na forma de uma lista de equipamentos e recursos no capítulo 5 representa um senário muito próximo ao que é proposto pelo instituto, em termos de recursos e equipamentos bem como a parametrização e os resultados esperados. Através deste estudo conclui-se que a caracterização proposta no trabalho, pode facilitar a implantação dos testes nas montadoras ou em laboratórios outorgados a validarem os protocolos NCAP.

\section{REFERENCIAS}

ANFAVE. ANFAVE. ANFAVE, 8 Dezembro 2017. Disponivel em: <http://www.anfavea.com.br/docs/08.12.17_PressRelease_ResolucoesCONTRAN.p df>. Acesso em: 20 maio 2018.

ASSOCIAÇÃO BRASILEIRA DE NORMAS TÉCNICAS. ABNT NBR ISO/IEC 17025. Associação Brasileira de Normas Técnicas. Rio de Janeiro, p. 2. 2005.

BERTOCCHI, M. Segurança Veicular. São Paulo: Skill, 2005.

BERTOCCHI, M. Segurança Veicular. São Paulo: Skill, 2005. ISBN 13.

EUROPEAN NEW CAR ASSESSMENT PROGRAMME. Euro Ncap - Adult Occupant Protection. The Dynamic Assessment of Car Seats For Neck Injury Protection Testing Protocol Version 3.1, Brussels, Junho 2011.

EUROPEAN NEW CAR ASSESSMENT PROGRAMME. Euro NCAP - Safety Assist. AEB Systems Version 2.0.1, Brussels, Novembro 2017. Disponivel em: <https://www.euroncap.com/en/for-engineers/protocols/safety-assist/>. Acesso em: maio 2018.

EUROPEAN NEW CAR ASSESSMENT PROGRAMME. TEST PROTOCOL - AEB systems. www.euroncap.com, União Européia, 2017. Disponivel em: $<$ https://www.euroncap.com/en/vehicle-safety/the-rewards-explained/autonomousemergency-braking/>. Acesso em: 20 maio 2018.

EURPEAN NEW CAR ASSESSMENT PROGRAMME. Euro NCAP - Safety Assist. AEB Systems Version 1.1, União Européia, jan. 2013. Disponivel em: <https://www.euroncap.com/en/for-engineers/protocols/safety-assist/>. Acesso em: abr. 2018.

GUIMARÂES, A. Eletrônica Embarcada Automotiva. São Paulo: Saraiva, 2016.

HADDON, W. Approaches to Prevention of Injuries. Approaches to Prevention of Injuries. São Caetano do Sul: Insurance Institute for Highway Safety. 1983. p. 2-3. 
LATIN NCAP NEW CAR ASSESSMENT PROGRAMME. Latin NCAP. Assessment Protocol Guidelines 2020-2023 version 1.0, Montevidéu, 25 Junho 2018. Disponivel em: <https://www.latinncap.com/en/our-tests/latin-ncap-advancedawards>. Acesso em: 15 jun. 2018.

LATIN NEW CAR ASSESSMENT PROGRAMME. TEST PROTOCOL - AEB systems. LATIN NCAP, fev. 2018. Disponivel em: <https://www.latinncap.com/en/our-tests/latin-ncap-advanced-awards>. Acesso em: 15 maio 2018.

MIYAGI, P. E. Controle Programável -Fundamentos do Controle de Sistemas a Eventos Discretos. $1^{\circ}$. ed. São paulo: Edgard Blocher LTDA, v. I, 1996.

ORGANIZAÇÃO DAS NAÇÕES UNIDAS. ONUBR. Nações Unidas BR, 24 Janeiro 2015. Disponivel em: <https://nacoesunidas.org/campanha/seguranca-transito/>. Acesso em: 15 Abril 2018.

POLÍCIA RODOVIÁRIA FEDERAL. Acidentes - PRF. Polícia Rodoviária Federal, dez. 2017. Disponivel em: <https://www.prf.gov.br/portal/dados-abertos/acidentes>. Acesso em: Agosto 2018.

SEECK, A. Safety Companion. Aschaffenburg: Carhs, 2017. ISBN 120.

WANG, Y.-Y. Safe Driving Capacity of Autonomous Vehicles. Electrical Engineering and Systems Science, Ithaca, 26 maio 2018. 2. Disponivel em: $<$ http://inovasorocaba.org.br/noticias/noticias-em-destaque/aea-debate-seguranca-eviabilizacao-de-veiculos-eletrificados-no-pais/>. Acesso em: 24 junho 2018. 